\title{
Dama Orchestra's shidaiqu recontextualized in theatre
}

\begin{abstract}
This article examines how Dama Orchestra has recontextualized shidaiqu (时代 曲) in a theatrical setting. Dama Orchestra was originally a Chinese orchestral group in Malaysia that, due to economic crisis, changed its focus from classical music to staging the more popularly demanded shidaiqu. Shidaiqu is a southern Chinese song genre popular from 1920 to 1950 and typically performed in Malaysia during Phor Tor (Hungry Ghost Festival). It has remained popular with mature Chinese Malaysian audiences at ko-tai, pubs, and karaoke bars. By adapting it to a theatrical form in the late 1990s, Dama Orchestra transformed the popular and commercial nature of these songs into an elite musical theatre genre. Performed as a Westernized hybrid theatre, shidaiqu attracted serious music aficionados in Malaysia and was raised from its stigmatized position as genü maichang (sing-song girl entertainment). This article draws on participant observation work to report how Dama musicians re-Sinicized the orchestration of shidaiqu and combined it with theatrical elements to appeal to the diasporic Chinese community of Malaysia.
\end{abstract}

Keyword: Dama Orchestra; Shidaiqu; Theatre; Chinese orchestral group; Malaysia 